\title{
Análise da Eficácia de Materiais de Proteção Su- perficial para Estruturas de Concreto Ambientes contaminados por Íons Cloreto
}

\author{
Albuquerque, D. V. S. \\ Escola Politécnica de Pernambuco \\ Universidade de Pernambuco \\ 50.720-001 - Recife, Brasil \\ diegopeb@hotmail.com
}

\author{
Monteiro E. C. B. \\ Escola Politécnica de Pernambuco \\ Universidade de Pernambuco \\ 50.720-001 - Recife, Brasil \\ nana.monteiro@uol.com.br
}

\begin{abstract}
Resumo Este trabalho tem como objetivo analisar a eficácia do uso dos variados tipos de proteção superficial que existem no mercado aplicado a corpos de prova. Essa avaliação se deu de forma comparativa através da realização de ensaios de absorção capilar, absorção por imersão e ensaio acelerado de corrosão. Para cada sistema de proteção superficial foram moldados dois corpos de prova, variando a relação água/cimento 0.4 e 0.7. Ao longo dos ensaios de absorção capilar e absorção por imersão, as grandezas medidas foram: massa dos corpos de prova (M) e Variação da massa (Mv). O método adotado permitiu uma avaliação de forma comparativa quanto à capacidade de absorção de líquidos e avaliação da corrosão através, respectivamente, dos ensaios de absorção e de corrosão acelerada. Diante disso, conclui-se que os corpos de prova com hidrofugante, para ambas as relações água/cimento, foram os que apresentaram melhor resultado no geral.
\end{abstract}




\section{Introdução}

Atualmente são incontáveis os casos nos quais as estruturas de concreto armado sofrem algum tipo de problemas, podendo ser estéticos, estruturais ou funcionais. Diante disso, a comunidade técnico-científica ao longo da última década vem realizando maneiras de combatê-los através de estudos e vastas discussões sobre a durabilidade das estruturas de concreto, o que ocasionou em significativos avanços com relação a esse assunto. Assim, as estruturas devem, além de suportar os esforços que agem sobre ela, serem capazes de resistir a agentes agressivos presentes no meio ambiente onde elas foram construídas, pois estes são os principais causadores de patologias.

Umas das patologias mais comuns encontradas em estruturas de concreto armado é a corrosão de armaduras. Andrade (1997) em levantamento realizado no estado de Pernambuco constatou que a corrosão das armaduras é responsável pela maior parte da degradação das estruturas em concreto, sendo responsável por $62 \%$ dos casos de manifestações patológicas registradas nas edificações.

A corrosão das armaduras é uma das manifestações patológicas de maior gravidade nas obras civis no cenário mundial, sendo sua importância justificada pelo comprometimento da segurança estrutural que o fenômeno envolve em estágios avançados, pelos altos custos de recuperação e perdas, além da incidência/reincidência do fenômeno que é relativamente alta (CASCUDO, 2000).

O alto custo para a recuperação desse tipo de patologia, atrelado aos potenciais riscos à vida dos seres humanos, mostra a importância e a necessidade do desenvolvimento de materiais e técnicas que protejam as estruturas da contaminação por agentes agressivos oriundos do meio ambiente.

Diversas pesquisas e trabalhos, realizados no Brasil e no exterior, relatam que a principal causa da corrosão é a penetração de cloretos, entre eles Helene (1986), Carmona Filho e Morega (1988), Dal Molin (1988), Aranha (1994), Andrad e (1997), e outros pesquisadores que contribuíram significativamente nesse sentido.

O Brasil, cuja costa marinha possui cerca de $7491 \mathrm{~km}$, tem sua grande parcela da população situada no litoral, e essa acaba sofrendo com a grande ação dos íons cloretos provenientes da névoa salina nas estruturas de concreto expostas a mesma. Isso fez com que crescesse o desenvolvimento de produtos a fim de evitar a penetração desses agentes, entre os quais esta o tratamento superficial do concreto, que será o objeto de estudo desta dissertação.
A proteção superficial proveniente da utilização dos diversos tipos de materiais se mostrará eficaz através de avaliação dos mesmos para os diversos tipos de situações existentes. Isso fará com que se elabore um ferramental necessário para a eficácia desses materiais para determinadas necessidades, e que assim preencha algumas lacunas que foram deixadas pelos trabalhos.

\section{Procedimento Experimental}

\subsection{Estilos}

Foram moldados corpos de prova, prismáticos e cilíndricos com os seguintes materiais: Cimento Portland (CP II Z-32), areia oriunda da região e os materiais de proteção, que são: hidrofugante, formador de película e bloqueador de poros.

Tabela 1. Denominação das séries para o ensaio de absorção por imersão.

\begin{tabular}{|c|c|c|c|c|}
\hline Série & Produto & A/C & Cura & Traço \\
\hline R1 & Referência & 0,4 & 7 dias & $1: 1,3$ \\
\hline R2 & Referência & 0,7 & 7 dias & $1: 3$ \\
\hline H1 & Hidrofugante & 0,4 & 7 dias & $1: 1,3$ \\
\hline H2 & Hidrofugante & 0,7 & 7 dias & $1: 3$ \\
\hline F1 & $\begin{array}{c}\text { Formador de } \\
\text { película }\end{array}$ & 0,4 & 7 dias & $1: 1,3$ \\
\hline F2 & $\begin{array}{c}\text { Formador de } \\
\text { película }\end{array}$ & 0,7 & 7 dias & $1: 3$ \\
\hline B1 & $\begin{array}{c}\text { Bloqueador } \\
\text { de poros }\end{array}$ & 0,4 & 7 dias & $1: 1,3$ \\
\hline B2 & $\begin{array}{c}\text { Bloqueador } \\
\text { de poros }\end{array}$ & 0,7 & 7 dias & $1: 3$ \\
\hline
\end{tabular}

Tabela 2. Denominação das séries para o ensaio de absorção por capilaridade.

\begin{tabular}{|c|c|c|c|c|}
\hline Série & Produto & A/C & Cura & Traço \\
\hline R3 & Referência & 0,4 & 7 dias & $1: 1,3$ \\
\hline R4 & Referência & 0,7 & 7 dias & $1: 3$ \\
\hline H3 & Hidrofugante & 0,4 & 7 dias & $1: 1,3$ \\
\hline H4 & Hidrofugante & 0,7 & 7 dias & $1: 3$ \\
\hline F3 & $\begin{array}{c}\text { Formador de } \\
\text { película }\end{array}$ & 0,4 & 7 dias & $1: 1,3$ \\
\hline F4 & $\begin{array}{c}\text { Formador de } \\
\text { pelicula }\end{array}$ & 0,7 & 7 dias & $1: 3$ \\
\hline B3 & $\begin{array}{c}\text { Bloqueador de } \\
\text { poros }\end{array}$ & 0,4 & 7 dias & $1: 1,3$ \\
\hline B4 & $\begin{array}{c}\text { Bloqueador de } \\
\text { poros }\end{array}$ & 0,7 & 7 dias & $1: 3$ \\
\hline
\end{tabular}


Tabela 3. Denominação das séries para o ensaio de potencial de corrosão.

\begin{tabular}{|c|c|c|c|c|c|}
\hline Série & Produto & A/C & Cura & Traço & $\begin{array}{c}\text { Presença } \\
\text { de ions } \\
\text { cloreto }\end{array}$ \\
\hline R5 & Referência & 0,4 & 7 dias & $1: 1,3$ & - \\
\hline R6 & Referência & 0,4 & 7 dias & $1: 1,3$ & $1 \%$ \\
\hline R7 & Referência & 0,7 & 7 dias & $1: 3$ & - \\
\hline R8 & Referência & 0,7 & 7 dias & $1: 3$ & $1 \%$ \\
\hline H5 & Hidrofugant & 0,4 & 7 dias & $1: 1,3$ & - \\
\hline H6 & Hidrofugant & 0,4 & 7 dias & $1: 1,3$ & $1 \%$ \\
\hline H7 & Hidrofugant & 0,7 & 7 dias & $1: 3$ & - \\
\hline H8 & Hidrofugant & 0,7 & 7 dias & $1: 3$ & $1 \%$ \\
\hline F5 & $\begin{array}{c}\text { Formador de } \\
\text { pelicula }\end{array}$ & 0,4 & 7 dias & $1: 1,3$ & - \\
\hline F6 & $\begin{array}{c}\text { Formador de } \\
\text { película }\end{array}$ & 0,4 & 7 dias & $1: 1,3$ & $1 \%$ \\
\hline F7 & $\begin{array}{c}\text { Formador de } \\
\text { película }\end{array}$ & 0,7 & 7 dias & $1: 3$ & - \\
\hline F8 & $\begin{array}{c}\text { Formador de } \\
\text { pelicula }\end{array}$ & 0,7 & 7 dias & $1: 3$ & $1 \%$ \\
\hline B5 & $\begin{array}{c}\text { Bloqueador } \\
\text { de poros }\end{array}$ & 0,4 & 7 dias & $1: 1,3$ & - \\
\hline B6 & $\begin{array}{c}\text { Bloqueador } \\
\text { de poros }\end{array}$ & 0,4 & 7 dias & $1: 1,3$ & $1 \%$ \\
\hline B7 & $\begin{array}{c}\text { Bloqueador } \\
\text { de poros }\end{array}$ & 0,7 & 7 dias & $1: 3$ & - \\
\hline B8 & $\begin{array}{c}\text { Bloqueador } \\
\text { de poros }\end{array}$ & 0,7 & 7 dias & $1: 3$ & $1 \%$ \\
\hline
\end{tabular}

\subsection{Absorção}

\subsubsection{Absorção por Imersão}

Neste ensaio foram confeccionados corpos de prova cilíndricos de argamassa de $50 \mathrm{~mm}$ de diâmetro e $100 \mathrm{~mm}$ de altura, estes foram moldados de acordo com a NBR 7215/91. Os corpos-de-prova foram secos em estufa a $100^{\circ} \mathrm{C}$ até constância de massa e foram mantidos em ambiente de laboratório pelo período de 24 horas para esfriarem. Para este ensaio foram empregados 04 corpos-deprova para cada material estudado. A variação de massa foi acompanhada durante o período de 30 dias, contados do início do período de imersão.

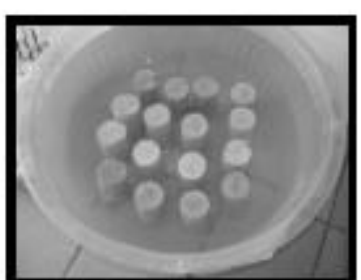

Figura 1. Ensaio de absorção por imersão.

\subsubsection{Absorção por Imersão}

Neste ensaio também foram utilizados corpos de prova cilíndricos de argamassa de $50 \mathrm{~mm}$ de diâmetro e $100 \mathrm{~mm}$ de altura, estes foram moldados de acordo com a NBR 7215 [9]. Os corpos de prova foram secos em estufa a $100^{\circ} \mathrm{C}$ até constância de massa e foram mantidos em ambiente de laboratório pelo período de 24 horas para esfriarem. Os sistemas de proteção foram aplicados na face circular correspondente ao fundo da forma. Foram utilizados 04 corpos-de-prova para cada material estudado. A variação de massa foi acompanhada durante o período de 30 dias, contados do início do período de imersão.

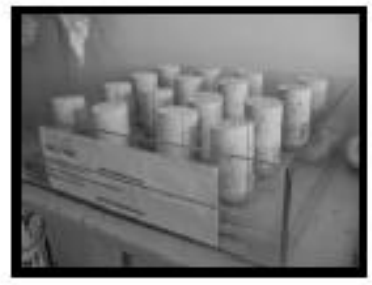

Figura 2. Ensaio de absorção por capilaridade.

\subsection{Absorção de Água}

Foram confeccionados corpos-de-prova com dimensões $60 \times 80 \times 25(\mathrm{~mm})$, armados com duas barras de aço longitudinais de diâmetro $5,0 \mathrm{~mm}, 100 \mathrm{~m}$ de comprimento e com cobrimento de $10 \mathrm{~mm}$. As barras foram dimensionadas com um comprimento maior, de modo a ficar com a sua extremidade exposta para possibilitar a conexão elétrica das armaduras para monitoramento da corrosão.

Existem duas séries de corpos de prova: uma com substrato previamente contaminado por cloretos $(1 \% \mathrm{em}$ relação a massa de cimento) e outra de concreto sem adição prévia de cloretos. Ambas foram submetidas a semi-ciclos de secagem e umectação.

As metodologias que envolvem os ciclos de secagem e umectação ou contato com solução de $\mathrm{NaCl}$, correspondem ao regime mais severo de penetração de cloretos (PAGE ET AL [13]). Os semi-ciclos caracterizam-se conforme a Tabela 4.

Tabela 4. Etapas do ensaio cíclico.

\begin{tabular}{lll}
\hline Semi-ciclo & Condição & Duração \\
\hline Secagem & Estufa a $50^{\circ} \mathrm{C}$ & 5 dias \\
Umectação & $\begin{array}{l}\text { Parcialmente submerso } \\
\text { em solução com } 3 \% \text { de }\end{array}$ & 2 dias \\
& $\mathrm{NaCl}$ & \\
\hline
\end{tabular}


A medição das variáveis estudadas foi feita ao final de cada semi-ciclo. As medições foram realizadas durante 8 ciclos (secagem + umectação) completos.

\section{Monitoramento e Avaliação da Corrosão}

O Potencial de corrosão (Ecorr ) pode ser considerado um indicador de deterioração e avalia os aspectos termodinâmicos associados à corrosão. A norma ASTM C - 876 [12] associa uma probabilidade superior a $95 \%$ de corrosão para valores de potenciais inferiores a $-350 \mathrm{mV}$, para eletrodo de cobre/ sulfato de cobre (Tabela 5).

Tabela 5. Critérios de avaliação das medidas dos potenciais de corrosão de acordo com a ASTM C876.

\begin{tabular}{lccc}
\hline $\begin{array}{l}\text { Potencial de corrosão em } \\
\text { relação ao eletrodo } \\
\text { referência de cobre-sulfato } \\
\text { cobre-CU/CUSO4 }(\mathbf{m V})\end{array}$ & $\begin{array}{c}\text { de } \\
\text { de }\end{array}$ & $\begin{array}{c}\text { Probabilidade de } \\
\text { corrosão (\%) }\end{array}$ \\
\hline Mais positivo que $-\mathbf{2 0 0}$ & 5 \\
\hline \\
Mais negativo que $\mathbf{- 3 5 0}$ & 95 \\
Entre -200 e -350 & Incerta \\
\hline
\end{tabular}

\section{Resultados e Discussões}

\subsection{Ensaios de absorção de água}

\subsubsection{Absorção por Imersão}

As Figuras 3 e 4 mostram os resultados obtidos para os corpos de prova referência e os três produtos aplicados na superfície dos corpos de prova (Hidrofugante, Formador de película e Bloqueador de poros).

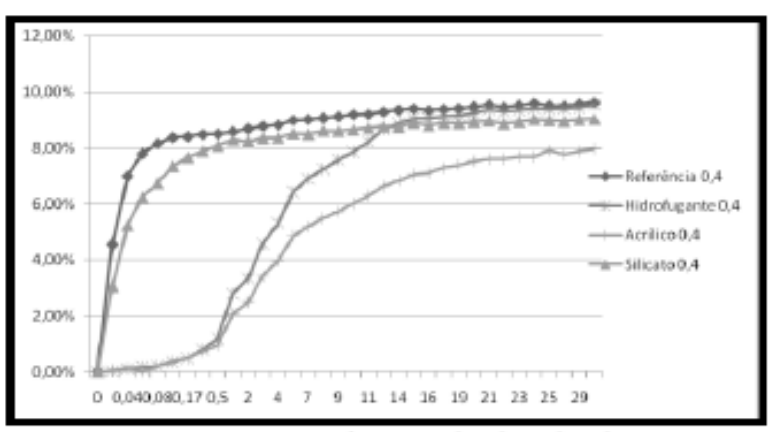

Figura 3. Comparação dos resultados da absorção por imersão (\%) dos corpos de prova (Referência,

Hidrofugante, Formador de película e Bloqueador de poros) com fator $\mathrm{a} / \mathrm{c} 0,4$.

Observa-se na Figura 3 que o produto Formador de Película $($ Acrílico 0,4) foi o que apresentou melhor resultado comparado com os outros produtos aplicados.
Logo o produto Hidrofugante foi o que apresentou o pior resultado comparado aos outros produtos ao fim do ensaio.

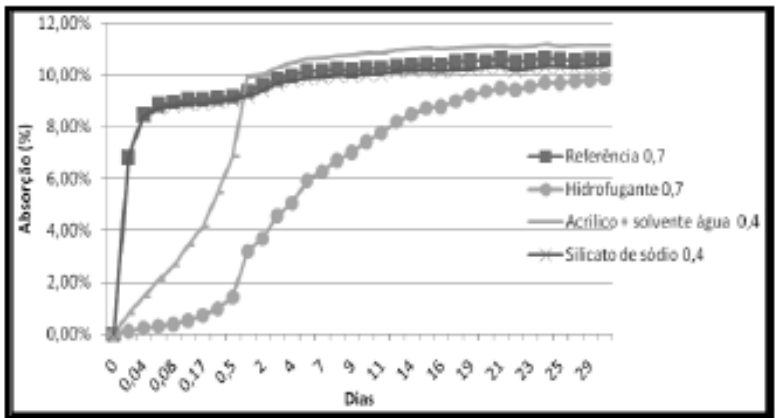

Figura 4. Comparação dos resultados da absorção por imersão (\%) dos corpos de prova (Referência,

Hidrofugante, Formador de película e Bloqueador de poros) com fator $\mathrm{a} / \mathrm{c} 0,7$

A Figura 4 mostra que para o fator a/c 0,7 o produto que apresentou melhor resultado foi o Hidrofugante, retardando a elevada absorção de água por mais tempo, enquanto que o Formador de película apresentou o pior resultado entre os três produtos aplicados, bem como quando comparado ao de Referência.

\subsubsection{Absorção por Capilaridade}

As Figuras 5 e 6 mostram os resultados obtidos para os corpos de prova referência e os três produtos aplicados na superfície dos corpos de prova (Hidrofugante, Formador de película e Bloqueador de poros).

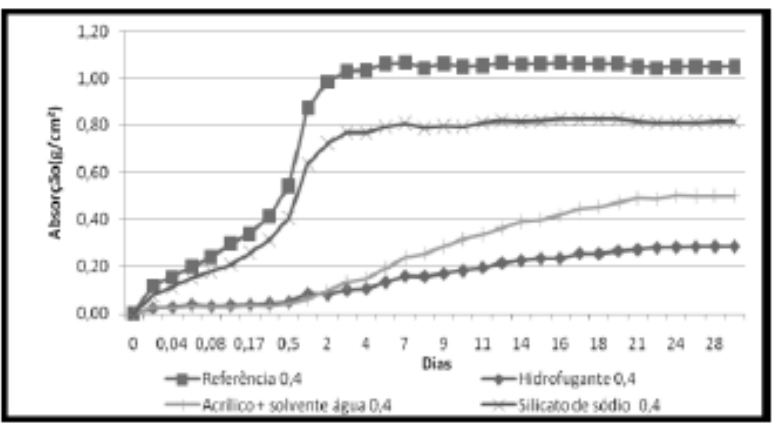

Figura 5. Comparação dos resultados da absorção por capilaridade $\left(\mathrm{g} / \mathrm{cm}^{2}\right)$ para o referência e o

Hidrofugante, Formador de película e Bloqueador de poros para o fator $\mathrm{a} / \mathrm{c} 0,4$. 


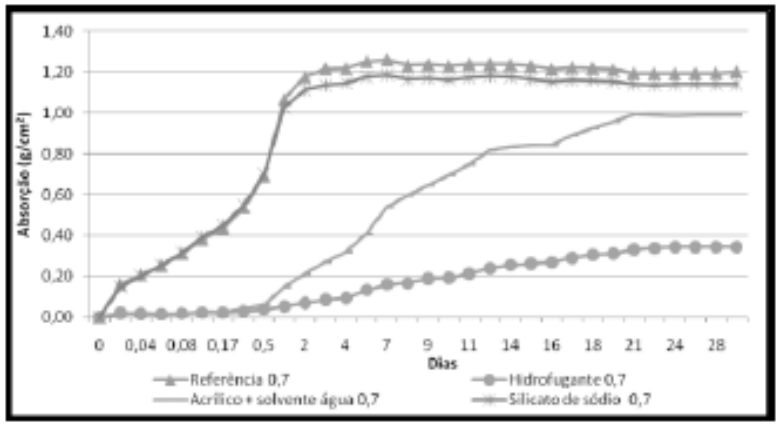

Figura 6. Comparação dos resultados da absorção por capilaridade $\left(\mathrm{g} / \mathrm{cm}^{2}\right)$ para o referência e o

Hidrofugante, Formador de película e Bloqueador de poros para o fator $\mathrm{a} / \mathrm{c} 0,7$.

Conforme pode se observar nas figuras acima, ambas as relações a/c analisadas mostram que o produto Hidrofugante apresentou o melhor desempenho, enquanto que o Bloqueador de poros foi o produto que apresentou pior desempenho.

\subsubsection{Absortividade}

As Figuras 7 e 8 se referem aos resultados obtidos para os corpos de prova referência e os três produtos aplicados na superfície dos corpos de prova (Hidrofugante, Formador de película e Bloqueador de poros).

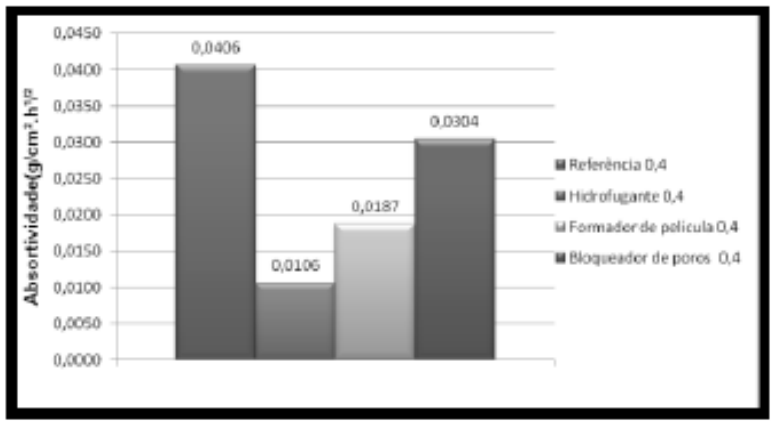

Figura 7. Comparação dos resultados da Absortividade $\left(\mathrm{g} / \mathrm{cm}^{2} \mathrm{t}^{1 / 2}\right)$ para o Referência e o Hidrofugante, Formador de película e Bloqueador de poros para o fator $\mathrm{a} / \mathrm{c} 0,4$.

Observa-se na Figura 7 que o fator a/c 0,4 o produto Hidrofugante foi o que apresentou o melhor resultado entre todos os produtos aplicados, reduzindo significativamente a absortividade, em torno de $74 \%$, enquanto que o produto Formador de película e Bloqueador de poros atingiram taxas de redução de $54 \%$ e $25 \%$, respectivamente.

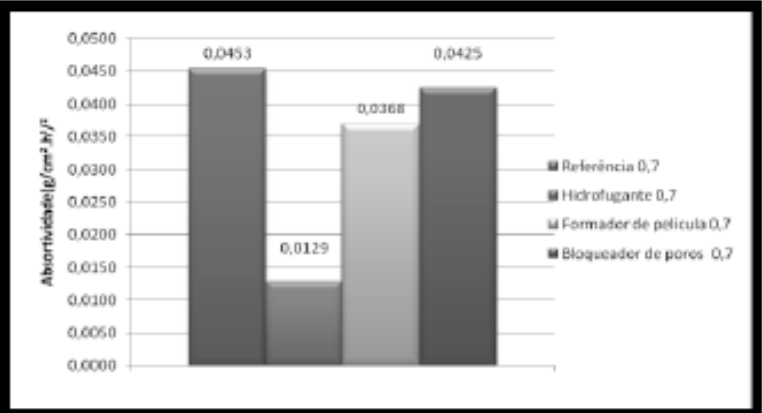

Figura 8. Comparação dos resultados da Absortividade $\left(\mathrm{g} / \mathrm{cm}^{2} \cdot \mathrm{t}^{1 / 2}\right)$ para o Referência e o Hidrofugante, Formador de película e Bloqueador de poros para o fator $\mathrm{a} / \mathrm{c} 0,7$.

$\mathrm{O}$ mesmo ocorreu para o fator a/c 0.7 , o produto que apresentou melhor resultado foi o Hidrofugante reduzindo a absortividade, em torno de $72 \%$, enquanto que o produto Formador de película e Bloqueador de poros atingiram taxas de redução de $19 \%$ e $6 \%$, respectivamente.

De acordo com os dados obtidos, viu-se que o produto Hidrofugante teve o melhor desempenho, quanto à capacidade de redução da absortividade, seguido pelo produto Formador de película, e por fim o produto Bloqueador de poros apresentou o pior desempenho.

\subsection{Potencial de Corrosão}

\subsubsection{Corpos de Prova sem adição de clore- tos}

As Figuras 9 e 10 mostram aos resultados obtidos para os corpos de prova referência e os três produtos aplicados na superfície dos corpos de prova (Hidrofugante, Formador de película e Bloqueador de poros).

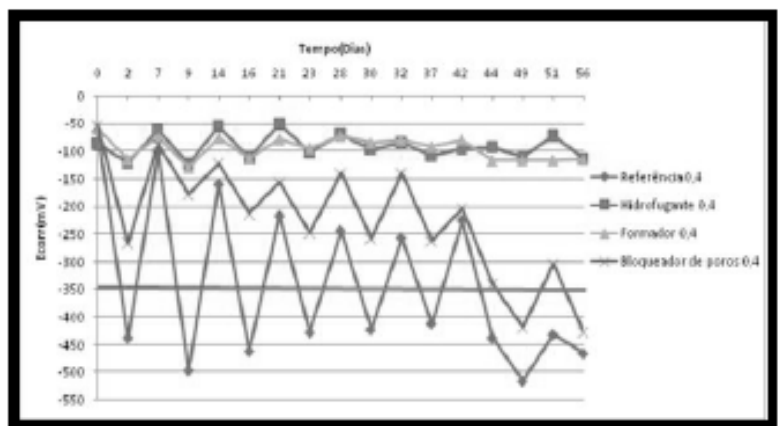

Figura 9. Comparação dos resultados de Potencial de corrosão $(\mathrm{mV})$ para os corpos de prova Referência,

Hidrofugante, Formador de película e o Bloqueador de poros, Fator a/c 0,4, sem adição de cloretos (potencial relativo ao eletrodo de cobre/sulfato de cobre). 
Conforme pode ser observado na Figura 9 para o fator a/c 0,4 os produtos Hidrofugante e Formador de película tiveram o melhor resultado, apresentando comportamentos semelhantes no que diz respeito ao potencial de corrosão. Já o Bloqueador de poros foi o que obteve o pior resultado, resultando na despassivação de suas armaduras ao final do $6^{\circ}$ ciclo.

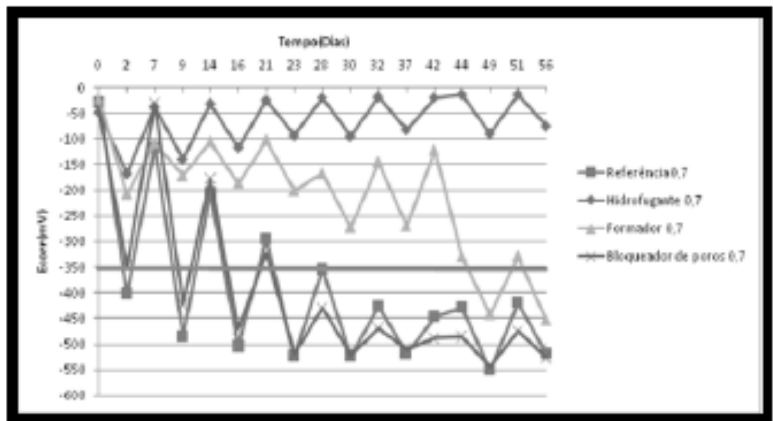

Figura 10. Comparação dos resultados de Potencial de corrosão (mV) para os corpos de prova Referência,

Hidrofugante, Formador de película e o Bloqueador de poros, Fator a/c 0,7 , sem adição de cloretos (potencial relativo ao eletrodo de cobre/sulfato de cobre).

Para o fator a/c 0.7 o produto que apresentou melhor resultado também foi o Hidrofugante. O Formador de película que tinha apresentado bom resultado para o fator a/c 0.4 , acabou apresentando maior amplitude nos valores de Ecorr para o fator a/c 0.7, vindo a despassivar suas armaduras ao fim do $7^{\circ}$ ciclo. Já o Bloqueador de poros apresentou comportamento semelhante ao de Referência para o fator a/c 0.7 , despassivando a armadura no $4^{\circ}$ ciclo.

De acordo com os dados obtidos, viu-se que o produto Hidrofugante teve o melhor desempenho, quanto ao potencial de corrosão, seguido pelo produto Formador de película, e por fim o produto Bloqueador de poros apresentou o pior desempenho.

\subsubsection{Corpos de Prova com adição de clore- tos}

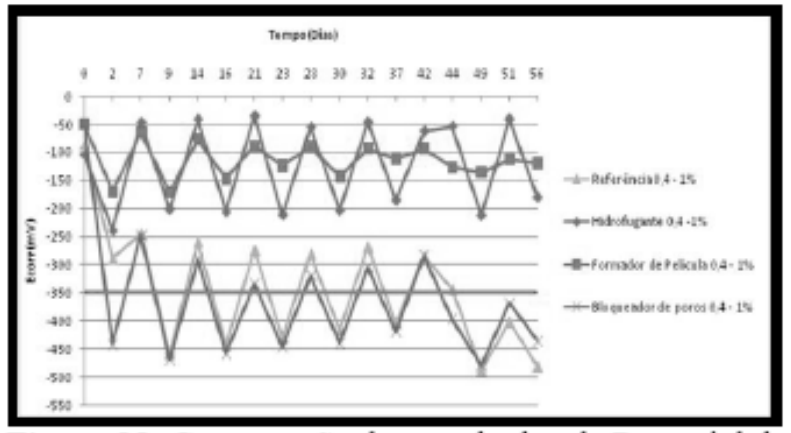

Figura 1l. Comparação dos resultados de Potencial de corrosão (mV) para os corpos de prova Referência, Hidrofugante, Formador de película e o Bloqueador de poros, Fator a/c 0,4, com adição de cloretos (potencial relativo ao eletrodo de cobre/sulfato de cobre).

Observa-se na Figura 11 que para o fator a/c 0.4 os produtos Hidrofugante e Formador de Película apresentaram melhor resultado no que diz respeito a restringir o acesso de água, evitando a corrosão das armaduras. O Bloqueador de poros foi o que apresentou o pior desempenho entre os três produtos.

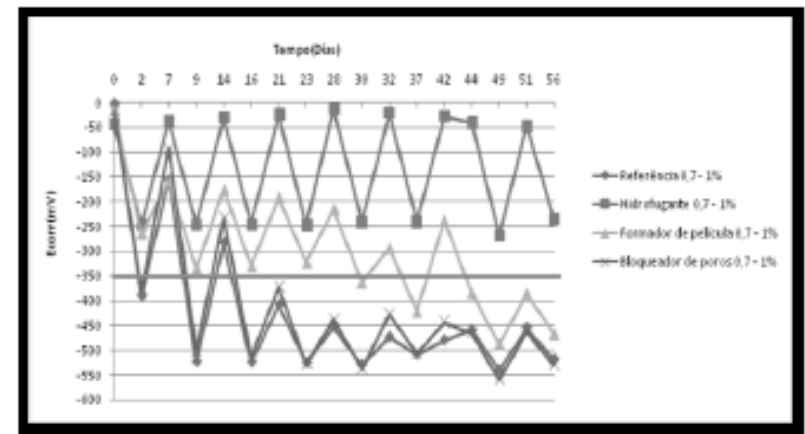

Figura 12. Comparação dos resultados de Potencial de corrosão (mV) para os corpos de prova Referência, Hidrofugante, Formador de película e o Bloqueador de poros, Fator a/c 0,7, com adição de cloretos (potencial relativo ao eletrodo de cobre/sulfato de cobre).

Para o fator a/c 0.7 o produto que apresentou melhor resultado foi o Hidrofugante, este evitou a corrosão durante o período de realização do ensaio. O produto Formador de película conseguiu retardar o processo de corrosão, mas não evitou que a mesma acontecesse ao fim do $7^{\circ}$ ciclo. O Bloqueador de poros também teve desempenho inferior ao restante dos materiais para este relação água/cimento, apresentando valores de potencial de corrosão inferiores a $-350 \mathrm{mV} \operatorname{logo}$ no início do $1^{\circ}$ ciclo.

De acordo com os dados obtidos, viu-se que o produto Hidrofugante teve o melhor desempenho, quanto ao potencial de corrosão, seguido pelo produto Formador de 
película, e por fim o produto Bloqueador de poros apresentou o pior desempenho.

\section{Conclusões}

Considerando as condições de ensaios aqui apresentadas podemos concluir para as os materiais estudados:

- A redução água/cimento teve como resultado melhorar o desempenho dos três tipos de produtos utilizados para a proteção superficial, quanto à absorção de água e conseqüentemente corrosão de armaduras por íons cloretos;

- Os corpos de prova confeccionados com o material hidrofugante apresentaram um desempenho comparativamente melhor que os confeccionados com os demais materiais quanto à absorção de água e conseqüentemente à corrosão por cloretos, principalmente para a relação água/cimento 0,4 ;

- Com a técnica utilizada, foi possível classificar os materiais estudados em ordem decrescente de desempenho, quanto às ambientes contaminados por cloretos:

\section{Hidrofugante $>$ Formador de Película $>$ Bloqueador de poros}

\section{Referências}

[1] ANDRADE, J. J. O. Durabilidade das estruturas de concreto armado: análise das manifestações patológicas nas estruturas no estado de Pernambuco (Dissertação de Mestrado). Universidade Federal do Rio Grande do Sul, 1997

[2] NINCE, A. A. Levantamento de Dados sobre a Deterioração de Estruturas na Região CentroOeste. Dissertação de Mestrado, Brasília, UnB, 1996

[3] ALONSO, M. C. ; ANDRADE, C. Corrosion of steel reinforcement in carbonated mortar containing chloride. Advanced Cement Research, v.1, 1988.

[4] MONTEIRO, E.C.B. Estudo da capacidade de proteção de alguns tipos de cimentos nacionais, em relação à corrosão de armaduras, sob a ação conjunta de CO2 e íons cloretos. 1996. 138p. Dissertação (Mestrado) - Departamento de Engenharia Civil, Universidade de Brasília. Brasília
[5] FIGUEIREDO, E. J. P. (1994). Avaliação do desempenho de revestimentos para proteção da armadura contra corrosão através de técnicas eletroquímicas - contribuição ao estudo de reparo de estruturas de concreto armado. Tese Doutorado - Escola Politécnica, Universidade de São Paulo, São Paulo, 423p.

[6] ASSOCIAÇÃO BRASILEIRA DE NORMAS TÉCNICAS - ABNT - NBR 9778. (1987) “Argamassa e concreto endurecidos - determinação da absorção de água por imersão - índice de vazios e massa específica". Rio de Janeiro.

[7] ASSOCIAÇÃO BRASILEIRA DE NORMAS TÉCNICAS. NBR 9779: Argamassa e concreto endurecidos - Determinação da absorção de água por capilaridade. Rio de Janeiro, 1995. 